\title{
THE NOVEMBER MEETING IN ATLANTA
}

The six hundred fifth meeting of the American Mathematical Society was held at the Georgia Institute of Technology in Atlanta, Georgia, November 15-16, 1963. There was a registration of 204, including 153 members of the Society.

By invitation of the Committee to Select Hour Speakers for Southeastern Sectional Meetings, Professor Fred B. Wright of the Tulane University of Louisiana addressed the Society. Professor Wright spoke on Invertible elements in Banach algebras at 2:00 P.M. on Friday, November 15.

Tallahassee, Florida

M. L. Curtis, Associate Secretary 